\title{
Functional Examination of the Upper and Lower Airways in Asthma and Respiratory Allergic Diseases: Considerations in the Post-SARS-CoV-2 Era
}

\author{
Olaguibel JM ${ }^{1,9}$, Alobid ${ }^{2,3,9}$, Alvarez Puebla $\mathrm{M}^{1,9}$, Crespo-Lessmann $\mathrm{A}^{4,9}$, Domínguez Ortega J 5,9, García-Rio F,9, \\ Izquierdo-Domínguez $A^{2,7}$, Mullol J,9, Plaza V ${ }^{4,9}$, Quirce $\mathrm{S}^{5,9}$, Rojas-Lechuga MJ3 , Valvere-Monge $\mathrm{M}^{8}$, Sastre J ${ }^{8,9}$ \\ 'Department of Allergy, Complejo Hospitalario de Navarra, Pamplona, Spain \\ 2Unidad Alergo-Rino, Centro Médico Teknon, Barcelona, Spain \\ ${ }^{3}$ Unitat de Rinologia \&t Clínica de l'Olfacte, Servei d'Oto-rino-laringologia, Hospital Clinic Barcelona; Immunoalèrgia Respiratòria Clínica i \\ Experimental, IDIBAPS; Universitat de Barcelona, Barcelona, Spain \\ ${ }^{4}$ Department of Respiratory Medicine, Hospital de la Santa Creu i Sant Pau; Institut d'Investigació Biomédica Sant Pau (IIB Sant Pau), Universitat \\ Autònoma de Barcelona, Department of Medicine, Barcelona, Spain \\ ${ }^{5}$ Department of Allergy, Hospital Universitario La Paz-IdiPAZ, Madrid, Spain \\ ${ }^{6}$ Department of Respiratry Medicine. Hospital Universitario La Paz-IdiPAZ, Madrid, Spain; Departamento de Medicina, Facultad de Medicina, \\ Universidad Autónoma de Madrid, Madrid, Spain \\ 7Department of Allergy, Consorci Sanitari de Terrassa; Clínica Diagonal, Barcelona, Spain \\ ${ }^{8}$ Department of Allergy, Fundación Jiménez Díaz, Madrid, Spain \\ ${ }^{9} \mathrm{CIBER}$ de Enfermedades Respiratorias (CIBERES), Spain
}

J Investig Allergol Clin Immunol 2021; Vol. 31(1): 17-35

doi: 10.18176/jiaci.0625

\begin{abstract}
Airway examination procedures can potentially transmit infectious diseases to patients and to the health care professionals who perform them via various mechanisms. The COVID-19 pandemic has halted most of the activity of the clinics and laboratories involved in assessment of lung and nasal function, and clear recommendations in this regard have been made. Today, we still do not know for sure what its consequences will be in the short or long term, since important gaps remain in our knowledge of aspects as fundamental as virus transmission mechanisms, pathophysiology, immune response, and diagnosis.

In this review, we study the examination techniques used to assess patients with respiratory allergy, asthma, and associated diseases during this period and highlight their possible advantages and disadvantages. Therefore, we focus on exploring the entire upper and lower airways, from the perspective of the safety of both health professionals and patients and their specific characteristics. We also analyze the intrinsic value of these interventions in terms of diagnosis and patient management.

The changing situation of COVID-19 may mean that some of the assertions presented in this review will have to be modified in the future. While we seek to ensure a consistently broad approach, some differences in operational details may apply owing to local regulations.

Key words: Asthma. Allergic rhinitis. Bronchial challenge. Inflammatory biomarkers. Lung function tests. Upper airway examination.
\end{abstract}

\section{Resumen}

Las técnicas de examen de las vías respiratorias son procedimientos que pueden transmitir enfermedades infecciosas, por diversos mecanismos, tanto a los pacientes, como a los profesionales de la salud que las realizan. La situación de pandemia debido a la enfermedad COVID-19 prácticamente ha detenido la mayor parte de la actividad de los laboratorios de función pulmonar y nasal, con recomendaciones, específicas, de múltiples sociedades y guías nacionales e internacionales. Continuamos viviendo las distintas olas de la pandemia y todavía no sabemos con certeza, cuáles serán sus consecuencias a corto o largo plazo, pues existen lagunas importantes en el conocimiento de aspectos tan fundamentales como los mecanismos de transmisión del virus, su fisiopatología y respuesta immune, o su diagnóstico.

En esta revisión examinaremos las diferentes técnicas de examen disponibles en la evaluación de pacientes que sufren enfermedades alérgicas como la rinitis o el asma y enfermedades asociadas a ellas, destacando sus posibles ventajas y desventajas, en esta era que estamos viviendo tras la aparición del SARS CoV-2. Por esta razón, queríamos centrarnos en explorar todas las vías aéreas superiores e inferiores. Lo haremos desde la perspectiva de la seguridad tanto de los profesionales de la salud como de los pacientes y sus características específicas. Paralelamente abordaremos el análisis del valor intrínseco que proporcionan estas intervenciones desde el punto de vista tanto del diagnóstico como del tratamiento de estos pacientes. 
La situación cambiante de esta enfermedad puede causar en el futuro, modificaciones de las afirmaciones presentadas en esta revisión. Si bien esta guía busca garantizar un enfoque amplio y consistente, puede ser necesario aplicar algunas diferencias en los detalles operativos, debido a las distintas regulaciones o situaciones locales.

Palabras clave: Asma. Rinitis alérgica. Provocación bronquial. Biomarcadores inflamatorios. Pruebas de función pulmonar. Examen de las vías respiratorias superiores.

\section{Introduction}

Airway examination procedures can potentially transmit infectious diseases to patients and to the health professionals who perform them via various mechanisms, including aerosols. The COVID-19 pandemic has halted most of the activity of the clinics and laboratories that assess lung and nasal function, with clear recommendations in this regard from multiple national and international societies and guidelines [1-3]. Today, we still do not know for sure what its consequences will be in the short or long term, since there remain important gaps in our knowledge of aspects as fundamental as virus transmission mechanisms, pathophysiology, immune response, and diagnosis. Furthermore, no reliable curative or preventive therapy has become available.

The COVID-19 crisis has made us aware of our responsibility in the transmission of infectious respiratory diseases. There is no doubt that new systems, protocols, and assumptions will emerge within the field of functional exploration and that these will completely replace many of those considered valid to date. In such uncertain circumstances, it seems reasonable to envisage scenarios where the properties considered necessary in our new reality are safe and lasting [4]. Within the field of lung function assessment, the approaches that have always seemed of value include protocols, standardization of investigations, and the protection of health care personnel. Our so-called new normal will make us question the value of all our interventions, without forgetting the importance of objective diagnosis, in a disease such as asthma, on which so much research has been performed.

In this review, we examine possible scenarios during the postpandemic period based on the various examination techniques used in patients with respiratory allergy and asthma and associated diseases, highlighting possible advantages and disadvantages. Therefore, we focus on examination of the entire upper and lower airways. We also review different scenarios from the perspective of the safety of both health care professionals and patients and determine their specific characteristics. At the same time, we analyze the intrinsic value that these interventions provide in terms of diagnosis and management of affected patients.

\section{Mechanisms of Transmission of SARS-CoV-2}

The 4 possible routes of exposure to viral respiratory infections, which are represented in the Figure and summarized in Table 1, are as follows: (1) contact between the hands and fingers and surfaces or objects contaminated by the virus (fomites) and subsequent contact between the fingers and the eyes, nostrils, and lips; (2) spray of droplets, consisting in direct projection of the virus transported in the first and larger cough or sneeze particles, generally with an aerodynamic diameter (AD) greater than $100 \mu \mathrm{m}$ on membranes of the face; (3) inhalation of viruses carried in airborne cough or secondary sneeze particles (which have an AD of between 5 $\mu \mathrm{m}$ and $100 \mu \mathrm{m}$ ) inhalable but nonbreathable particles that are usually deposited on the upper airways and conjunctiva, and finally, although perhaps less important in viruses such as influenza; (4) inhalation of viruses transported in the air in small particles of less than $5 \mu \mathrm{m} \mathrm{AD}$, which are therefore breathable and originate, after an initial evaporation process, from coughing, sneezing, speech, exhalation maneuvers, and breathing itself. Respirable particles are deposited throughout the respiratory tract, including the alveolar region, whereas inspirable particles are deposited in the upper respiratory tract and major tracheobronchial regions [5]. Unlike routes 1 and 4 , routes 2 and 3 require close contact, generally defined as being less than 1 or 2 meters from the possible transmitter. These pathways vary in importance for each different infectious agent, and they continue to be the subject of much controversy [6]. Current data suggest that transmission of severe acute respiratory syndrome coronavirus 2 (SARS-CoV-2) infection occurs from person to person primarily during close exposure to a person infected with the virus and through respiratory droplets produced when the infected person speaks, coughs, or sneezes. These droplets may fall into the mouth, nose, or eyes of people who are nearby or may be inhaled. Transmission can also occur through contact with contaminated surfaces followed by contact with the eyes, nose, or mouth. Consequently, public health bodies have focused on 3 main measures: frequent and thorough hand washing; social distancing; and good respiratory hygiene. General hand hygiene is considered the cornerstone of prevention and is essential to minimize the colonization and transmission of the virus [7]. An update on hand hygiene recommends a modification of the WHO I formulation with $6 \mathrm{~mL}$ for 60 seconds $(80 \% \mathrm{wt} / \mathrm{wt}$ ethanol, $0.125 \% \mathrm{vol} / \mathrm{vol}$ hydrogen peroxide, and $0.50 \% \mathrm{vol} / \mathrm{vol}$ glycerol) or with $3 \mathrm{~mL}$ for 30 seconds for a modification of the WHO II formulation (75\% wt/wt isopropanol, $0.125 \% \mathrm{vol} / \mathrm{vol}$ hydrogen peroxide, and $0.50 \% \mathrm{vol} / \mathrm{vol}$ glycerol) [8]. It is also essential to perform routine cleaning and disinfection of environmental and other frequently touched surfaces, together with complete cleaning of rooms after every procedure 
Table 1. Commonly Accepted Respiratory Routes of Viral Transmission ${ }^{a}$

\begin{tabular}{|c|c|c|}
\hline $\begin{array}{l}\text { Transmission } \\
\text { Route }\end{array}$ & Particles Involved and Characteristics & Characteristics/Definition of Transmission \\
\hline Contact & & Self-inoculation of mucous membranes by contaminated hands \\
\hline Direct & Deposited on persons & Virus transfer from one infected person to another \\
\hline Indirect & Deposited on objects & $\begin{array}{l}\text { Virus transfer through contaminated intermediate objects } \\
\text { (fomites) }\end{array}$ \\
\hline \multicolumn{3}{|l|}{ Airborne } \\
\hline Droplet & $\begin{array}{l}\text { Droplets }(>5 \mu \mathrm{m}) \\
\text { Remain in air for a short time }(<2 \mathrm{~min}) \\
\text { Dispersed over short distances }(1-2 \mathrm{~m})\end{array}$ & $\begin{array}{l}\text { Short range transmission. } \\
\text { Direct inoculation on an uninfected person through } \\
\text { coughing/sneezing/breathing of infected person. } \\
\text { Deposition mainly on mucous membranes and upper respiratory tract. }\end{array}$ \\
\hline Aerosol & $\begin{array}{l}\text { Aerosols, droplet nuclei }(<5 \mu \mathrm{m}) \\
\text { Remain in air for several hours } \\
\text { Dispersed over long distances }(1-10 \mathrm{~m})\end{array}$ & $\begin{array}{l}\text { Long-range transmission } \\
\text { Inhalation of aerosols in respirable size range } \\
\text { Deposition along the respiratory tract, including the lower airways }\end{array}$ \\
\hline
\end{tabular}

${ }^{a}$ Modified from reference [5].

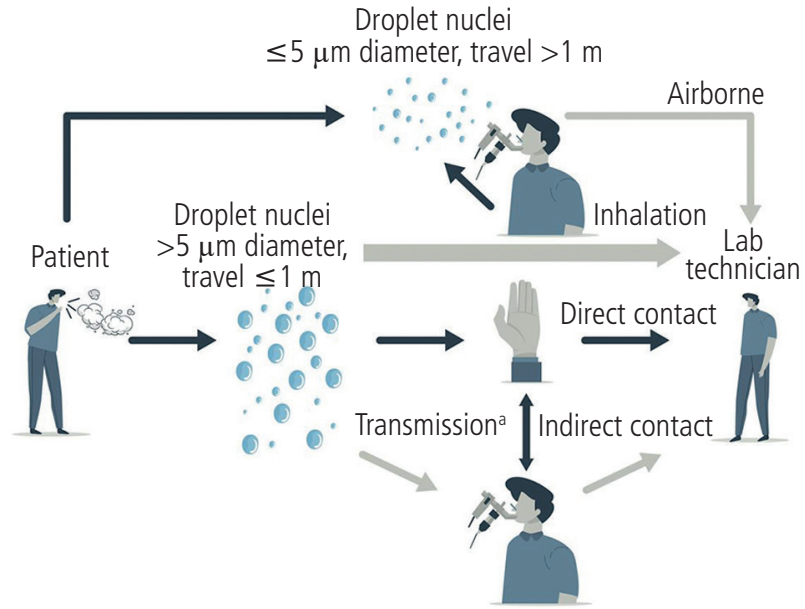

aTransmission routes involving a combination of hand and surface $=$ Indirect contact

Figure. Possible mechanisms of SARS-CoV-2 transmission during airway assessment.

New research has clearly demonstrated that transmission through aerosols or droplet nuclei is another important mechanism. Asadi et al [9] reported that SARS-CoV-2 is stable and remains infectious for several hours or days in aerosols and on surfaces: it is detected in aerosols up to 3 hours, in copper up to 4 hours, in cardboard up to 24 hours, and in plastic and stainless steel up to 2 to 3 days. During airway examination, transmission can also occur through routes 3 and 4 . It is well demonstrated that inspirable particles are large enough to carry a variety of respiratory pathogens, such as the measles virus, influenza virus, SARS-CoV, and SARS-CoV-2 [10]. They are also potentially more infectious, as they persist in the air for longer periods of time before submitting to gravity, thus increasing the likelihood of inhalation by susceptible individuals and the probability of further penetration of the respiratory tract to initiate an infection of the lower respiratory tract. Therefore, the top priority in preventing and mitigating the disease is avoiding breathing of airborne particles and cough-generated droplets. Additional measures are necessary for the protection of patients and health care personnel from breathable or inspirable particles. These include the use of more complex personal protective equipment (PPE) with potent face mask respirators and close control of ventilation/air conditioning systems [11] (see below). The emission capacity of breathable and inspirable particles is potentially highly variable depending on various circumstances such as the intensity of speech or the flow of exhalation [12]. Furthermore, superspreaders, that is, contagious individuals that infect a disproportionately large number of susceptible contacts, have been adequately documented in previous coronavirus pandemics, such as the MERS-CoV, SARS-CoV, and SARS-CoV-2 outbreaks [13].

\section{Environmental Considerations of Airborne Precaution Rooms (Ventilation)}

The association between ventilation, air movements in buildings, and the transmission/spread of infectious diseases, especially those caused by respiratory viruses, has been well demonstrated. In the COVID-19 era, most lung function guidelines recommend proper room ventilation and increased times between patient examinations [1-3]. The general purpose of ventilation in buildings is to provide healthy air both by diluting the pollutants originating in the building and by removing contaminants $[14,15]$. Ventilation introduces and distributes outdoor and/or properly treated recycled air into a building or a room. Together with other methods of isolation, it also reduces the risk of exposure to a pathogen or infected source hazard. Therefore, it is an important safety measure for patients and health care workers. 
Clearance of aerosols depends on ventilation and air change within a room. Increasing the ventilation rate can effectively reduce the risk of long-range airborne transmission but may be of little use in preventing droplet-borne transmission. Among the different types of ventilation, natural ventilation includes natural forces able to drive outdoor air through purposebuilt openings in the building envelope, including windows, doors, solar chimneys, wind towers, and trickle ventilators. This natural ventilation of buildings depends on the climate, building design, and human behavior. In naturally ventilated airborne isolation rooms, the airflow should be directed to areas free of transit or permit the rapid dilution of contaminated air into the surrounding areas and the open air [16]. Natural ventilation has many drawbacks, is variable, and depends on external climatic conditions. In addition, it may be difficult to control in terms of flow and direction and often does not work as expected. Regular operation may be interrupted. Therefore, instead of being an important tool for infection control, natural ventilation systems may result in the spread of infectious diseases in health care facilities.

Mechanical ventilation includes different types of fans. In a positive pressure system, the room air escapes through envelope leakages or other openings. In a negative pressure system, "sucking" air from the outside replaces room air. Room pressure may be maintained at either slightly positive or negative pressure by using an unequal supply or unequal exhaust ventilation rates [17]. Filtration systems can be installed in mechanical ventilation devices to remove harmful microorganisms, particulates, gasses, odors, and vapors. In an airborne precaution room for infection control, a minimum negative pressure of $2.5 \mathrm{~Pa}$ is often maintained relative to the corridor [18]. Mechanical ventilation is expensive to install and maintain in isolation rooms. It often does not deliver the recommended ventilation rate and may fail to maintain negative pressure. Hybrid or mixed-mode approaches are used when the natural ventilation flow rate is too low. An airborne precaution room can be naturally or mechanically ventilated but requires $\geq 12$ air changes per hour $(\mathrm{ACH})$ and controlled direction of airflow (CDC) (the World Health Organization recommends double, $160 \mathrm{~L} / \mathrm{s} /$ patient [hourly average ventilation rate]). Once an end to dispersion can be defined (such as the patient leaving the room), a single air change is estimated to remove $63 \%$ of airborne contaminants; a similar percentage is removed with each subsequent air change. After 5 air changes, less than $1 \%$ of the original airborne contamination is thought to remain.

In an isolation room with 10 to $12 \mathrm{ACH}$, a minimum of 30 minutes will reduce contamination to less than $1 \%$ (equivalent to $80 \mathrm{~L} / \mathrm{s} /$ patient in a $4 \times 2 \times 3-\mathrm{m}^{3}$ room). In a side room with $6 \mathrm{ACH}, 1$ hour would be a pragmatic time, enabling aerosols to settle and be removed by ventilation. While natural ventilation by opening windows and doors may generate a favorable $\mathrm{ACH}$ value, it relies on correct door and window operation. However, the rooms are not habitually operated with windows and doors open.

Appropriate maintenance of airflow direction from clean zones to dirty zones is very important. Appropriate airflow can be obtained using air pressure control technologies, albeit at a cost. Different requirements of pressure differences or imbalance of the airflow rate range from 2.5 to $15 \mathrm{~Pa}$. The required pressure difference should be used to avoid bidirectional flow, which occurs due to temperature difference and wind force.

Air conditioning systems may potentially cause droplet transmission. A recent report on a COVID-19 outbreak in China suggests that air conditioning contributed to the outbreak and to close contact between affected persons. Interestingly, smear samples from the air conditioner were negative for SARSCoV-2 by reverse transcription polymerase chain reaction (PCR) analysis [19].

In summary, there is sufficient and robust evidence to demonstrate the association between ventilation, air movements in buildings, and the transmission/spread of some infectious diseases. However, there are insufficient data to specify and quantify the minimum ventilation requirements in hospitals and isolation rooms with respect to airborne spread of infectious diseases [20-22].

\section{Protection of Health Care Workers}

A detailed description of all the issues involved in measures to protect health care workers is beyond the scope of this review, and extensive and specific guidelines have been published elsewhere [1-3]. As previously mentioned, the spread of respiratory viral infections occurs primarily through contact and droplet routes, although new research suggests SARS-CoV-2 can remain viable and infectious in aerosols for hours [9]. Therefore, the use of masks as appropriate PPE is often considered for prevention of the spread of respiratory infections. A recent meta-analysis of 21 studies provided the latest evidence on the efficacy of masks in preventing the transmission of the infection [23]. The authors concluded that the protective effects of masks were not only significant for healthcare workers and patients, but also consistent between Asian and Western populations. Because the disease is highly contagious, the use of a face filtering piece (FFP) respirator mask (FFP2 and FFP3) is recommended for all aerosolgenerating procedures when caring for patients. The FFP2 mask filters approximately $92 \%$ of air particles, protecting against nontoxic residues and fibrogenic elements and preventing the inhalation of toxic fluids, dust, aerosols, and fumes. The FFP3 mask filters $98 \%$ of air particles, protecting against poisons and toxins of dust, smoke, and aerosols, as well as bacteria, viruses, and fungal spores. For isolation procedures and where infectious aerosols might be generated, the WHO recommends using a respirator with a filtration efficiency of at least $95 \%$ for 0.3 -micron diameter particles, which is equivalent to an N95 facemask, according to the US National Institute for Occupational Safety and Health (NIOSH) regulations. Given that the US regulations differ from European regulations, this level of protection is between FFP2 and FFP3. Staff must additionally wear protective goggles and a waterproof apron or gown [16]. A Cochrane review concluded that for donning and doffing procedures, contamination can be reduced and adherence improved by adopting 1-step glove and gown removal, double-gloving, spoken instructions during doffing, and glove disinfection [24]. Another systematic review and meta-analysis supported physical distancing of $\geq 1 \mathrm{~m}$ and provided quantitative estimates for models and contact tracing [25]. Adequate preventive measures and the correct 
use of PPE are essential if we are to prevent the transmission of the disease and minimize the risks of personnel exposed to the aerosols generated during the examinations. All pulmonary function laboratories must follow guidelines for prevention and control of COVID-19 infection. Specific issues related to each procedure are addressed in the sections below.

\section{Patient Protection and Screening: Itinerary and Conditions of Access to the Pulmonary Function Laboratory}

\subsection{Organization}

As a general rule, pulmonary function tests should not be performed on patients with suspected or diagnosed COVID-19. According to the recommendations of the European Respiratory Society (ERS) [1] and the Spanish Society of Respiratory Pathology (SEPAR) [2], during the pandemic phase, spirometry should only be performed for the preoperative evaluation of surgery for lung cancer. Nevertheless, exceptions must be considered on a case-by-case basis. Once this phase has passed, spirometry will be prioritized when it is considered essential for clinical decision-making.

In the postpeak phase (phase 1 onwards), spirometry and bronchodilator testing can be performed following the guidelines and recommendations of the scientific societies ERS [1], SEPAR [2], and SEAIC [3], which are summarized below.

During the appointment, the patient will answer a preliminary screening questionnaire and, if there is no suspicion of COVID-19 infection, will be provided with the indications for interruption of the usual asthma treatment prior to the test, as well as the location (wing, room) and the examination time, with a request that they come 5 minutes in advance, but no sooner.

Patients will be instructed to attend the appointment alone, and a companion or caregiver will only be permitted when necessary.

\subsection{Waiting Room}

Blocking chairs will ensure a distance of 2 meters between patients, the room will lack objects that could facilitate transmission of fomites, and periodic cleaning will be intensified.

On arrival at the waiting room:

- The patient (and companion, if any) will be provided with a surgical mask, asked to occupy only 1 chair and to remain seated until called to the diagnostic laboratory.

- The patient's COVID-19 status will be assessed again by means of a screening questionnaire.

- If possible, the patient's forehead temperature will be monitored using a remote monitoring device. Only patients without suspected COVID infection will undergo spirometry. In other cases, the patient will be referred to the corresponding health care circuit.

\subsection{Pulmonary Function Test (Spirometry) Room}

A specific isolated room is used for spirometry, with minimum dimensions of $2.5 \times 2.5 \times 2.5 \mathrm{~m}$ and natural ventilation or individual air conditioning. The room must also have a sink. Only 1 patient can be in the room at any time, and the companion will not be allowed to enter.

The patients' appointments will be arranged so that there is twice the time to carry out the test. Vulnerability should be borne in mind in order to prevent infection in at-risk populations. It is advisable to reserve some appointments in the agenda for elderly patients, severe asthmatics, and people with other chronic or debilitating diseases. Children and adults should be separated, by means of different rooms or time slots.

Once the test is complete, the room will remain empty for at least 15 minutes to guarantee ventilation and cleaning. Ventilation must be performed taking into account the proposals presented in Section 2.

On entering the spirometry room:

- The patient must remove his/her gloves, if any, and wash his/her hands with a hydroalcoholic solution.

- The patient must be instructed not to touch any surface in the room.

- The facemask must be removed, from back to front, only during the test.

On leaving the spirometry room:

- The patient must wash his/her hands with a hydroalcoholic solution and put on the mask.

- The patient will be instructed that on arrival home, he/ she should wash his/her clothes in hot water and air out clothes that cannot be washed.

After completion of the test, the room will remain empty for at least 15 minutes for adequate ventilation and cleaning. Ventilation must be performed taking into account the proposals presented in Section 2.

\section{Spirometry}

As spirometry measures the maximum volume of air that an individual can inspire and expire with maximal effort, it constitutes a fundamental procedure in the assessment of general respiratory health. In asthma, spirometry plays a key role in ensuring a proper diagnosis of the disease and in the evaluation of patients at risk of an exacerbation [26].

The major goal of infection control should always be the prevention of transmission to patients and staff during maneuvers while the procedure is being performed. However, in a postpandemic scenario, additional safety precautions should be taken during spirometry, since, to a lesser extent than other lung function tests, spirometry can generate aerosols through its potency for coughing and droplet formation.

During the procedure, infection can also be transmitted through direct contact with surfaces. The health professional ought to maintain a minimum 1-m distance from the patient. Physical barriers could prove useful for avoiding direct contact with staff and/or equipment, and appropriate room ventilation is mandatory when negative pressure is not available in testing areas. To diminish the risk of infection, it is recommended to use disposable mouthpieces and noseclips and to clean the testing space between patients with appropriate cleaners and by wiping contact surfaces such as handheld spirometers, chair arms, tables, and close surfaces of tubing and valves. Wipes containing alcohol or other approved 
disinfectants should be used. In-line bacterial and viral filters with minimum proven efficiency for a high expiratory flow of 600-700 L/min are needed [1]. Laboratories should continue using their usual pneumotachographs as long as they meet American Thoracic Society/European Respiratory Society quality standards [28], and cleaning should follow the manufacturer's protocol. The protocol for pneumotachographs and all their removable parts requires a high-level cleaning and disinfection process, which includes cleaning with enzymatic cleaner or nonenzymatic detergent, disinfection by prolonged immersion in a disinfectant solution, rinsing with sterile water, and drying with sterile compresses. Prescreening of patients and use of antibacterial/antiviral filters are sufficient to enable this process to be carried out only at the end of each workday (morning or afternoon), although this approach is also exceptionally recommended after examining patients with a very intense cough or bronchorrhea. If an infectious disease is suspected, filters should be changed after examination or disposable pneumotachographs must be used. Furthermore, the pandemic requires volume to be calibrated whenever the pneumotachograph is changed and in the case of disposable pneumotachographs. If new lung function equipment is acquired, current circumstances may reinforce the choice of a disposable combined nozzle/pneumotachograph (eg, Lilly-type pneumotachographs).

PPE is necessary in all circumstances, and health professionals should be well trained in how to put on, remove, and dispose of this equipment [27]. FPP2 or FPP3 masks and eye protection (face shield or goggles) should be used, and nitrile gloves should be discarded after each patient. Standardized gowns and aprons should be adapted to the different phases of the pandemic. Hand hygiene with an alcohol-based hand rub should be performed between patients.

In settings with a very low pretest probability of infection, spirometry should be implemented according to conventional standards [28], although strict safety measures should be readopted if the risk-benefit ratio changes. Bronchodilator responsiveness testing must be performed with a bronchodilator administered via a metered-dose inhaler attached to a valvespacing chamber [1].

\section{Oscillometry}

Oscillometry is performed at tidal volume and is easily applicable in children and adults who are incapable or in whom it is not advisable to perform forced expiratory maneuvers. Potentially, oscillometry is less able to generate aerosols or induce cough. The technique is now well standardized and used in daily clinical practice. A positive bronchodilator response has been defined (an absolute increase in R5 equal to or greater than $40 \%$ of the baseline situation), thus facilitating its implementation as a diagnostic test [29]. Furthermore, various studies and computational lung models suggest that $5 \mathrm{~Hz}$ (R5) to $20 \mathrm{~Hz}$ (R20) resistance is an anatomically sensitive measure of small airway disease $[30,31]$. This parameter seems to have a close relationship with both asthma control and quality of life and can be used to predict responses to therapy, thus making it more apt for clinical use than classic spirometry parameters.

\section{Bronchial Challenge Tests}

Bronchial hyperresponsiveness is an abnormal increase in airflow limitation following exposure to a nonallergic or allergic stimulus. Bronchial hyperresponsiveness to stimuli such as allergens, methacholine, and hypertonic saline is a characteristic feature of asthma; nearly all patients with asthma exhibit increased responsiveness, although this is not specific and is also present in chronic obstructive pulmonary disease (COPD) [32]. In general, bronchial hyperresponsiveness is frequently used to help diagnose and characterize individuals with airway diseases. Methacholine bronchial challenge is especially relevant in ruling out asthma [32].

Bronchial challenge tests include the use of direct agents (direct effect on airway smooth muscle), such as methacholine or histamine, and indirect agents (act by causing the release of endogenous mediators), such as adenosine, mannitol, eucapnic voluntary hyperpnea with dry air $(\mathrm{EVH})$, nonisotonic aerosols, different types of exercise tests, aspirin/NSAIDs, and occupational and nonoccupational allergens.

Direct airway challenges have been widely used, are well standardized $[33,34]$, and are much more sensitive than indirect tests, although these are not interchangeable [35]. Indirect bronchial stimuli may reflect more directly ongoing airway inflammation and are therefore more specific for identifying active asthma or subtypes of asthma, such as exercise-induced bronchoconstriction (exercise test or EVH) [36].

The inhalation protocols of some agents (methacholine, histamine, adenosine, aspirin, allergens) include a dosimeter (5-breath method) and the 2-minute tidal breathing method with a breath-activated or continuous nebulizer. In both types of inhalation protocol, it is mandatory to use a validated expiratory filter to avoid contaminating room air with the bronchoconstriction substance and with the exhaled particles from the patients. The risk of expiratory leakage is reduced in the dosimeter technique, thus making it the recommended approach in the current situation. Since inhalation of nonisotonic aerosol requires high airflow nebulizers, this approach is not recommended. Mannitol inhaled as a dry powder could be another safe alternative [12], although it frequently induces cough. Bronchial challenge tests with allergens are seldom indicated. Still, they may reveal a direct relationship between the allergen and the bronchial response and make it possible to study the mechanisms of disease and the efficacy of a therapeutic intervention [37]. Bronchial challenge with occupational agents is more frequent, since it is considered the gold standard for demonstrating occupational asthma/hypersensitivity pneumonitis and is therefore necessary in some cases [38]. These challenges should be performed in enclosed challenge rooms equipped with an adequate exhaust ventilation system or using closedcircuit devices.

The recommendations suggested for preventing exposure to potentially harmful aerosols (technicians and patients) during bronchial challenge tests are summarized in Table 2. Performing RT-PCR immediately before the procedure should be considered. 


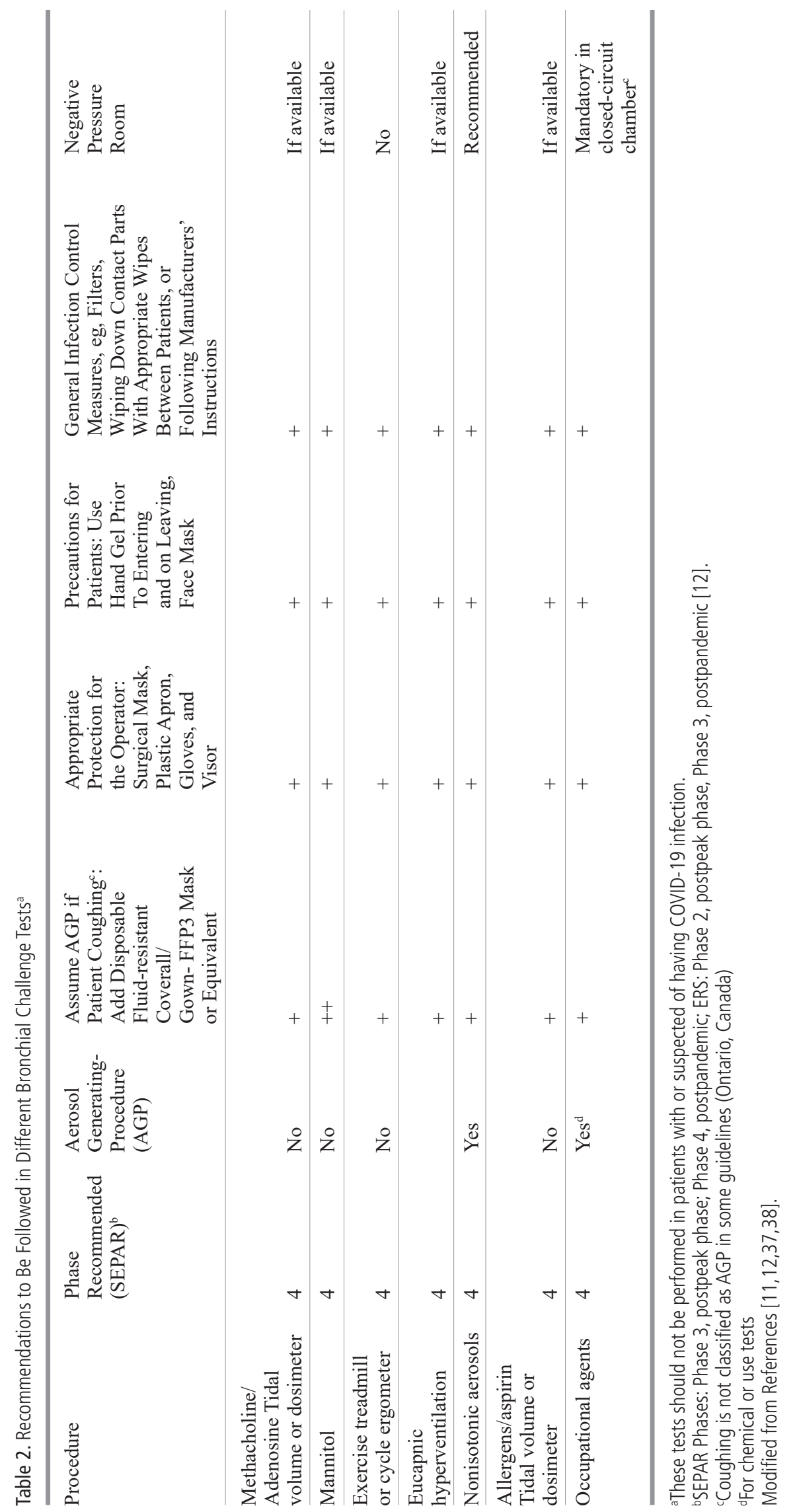




\section{Lung Volumes}

Lung volume testing provides indices such as total lung capacity (TLC), residual volume (RV), and functional residual capacity (FRC), which are useful for assessing lung mechanics. Measurement by plethysmography and dilutional gas methods are widely standardized [41]. Although it may slightly overestimate lung volumes [42], plethysmography is the preferred method in patients with asthma, because dilutional methods lead to greater underestimation of lung volumes [43]. Moreover, plethysmography provides an indication of the severity of asthma [44].

The main indications for plethysmography in asthma are identification of air trapping, evaluation of lung hyperinflation, assessment of obese patients with asthma, and confirmation of a restrictive disorder. Air trapping, which is usually defined as an increase in $\mathrm{RV}$ or the RV/TLC ratio, is frequent in patients with severe asthma [45] and is associated with inflammation [46] and airway responsiveness [47]. Some studies have reported normalization of RV in patients with nonsevere asthma receiving inhaled corticosteroids [45] or after treatment with montelukast [47]. Others indicate that air trapping may be the first functional manifestation of mild asthma, before the development of spirometry abnormalities [48].

Plethysmography is necessary to detect lung hyperinflation, which may be caused by airway narrowing or by loss of elastic recoil, thus increasing FRC [45]. Evaluation of this disorder is particularly important in asthmatic patients with fixed obstruction, because it has been attributed to an increase in the distensibility of lung parenchyma [49].

In obese patients with asthma, the determination of lung volumes makes it possible to determine the impact of both entities on lung function and, eventually, on respiratory symptoms. Unlike asthma, obesity causes a decrease in FRC and $\mathrm{RV}$, with an even greater reduction in expiratory reserve volume [50]. On other occasions, it is necessary to know lung volume values to confirm or rule out possible restrictive abnormalities, which have been reported in up to $8 \%$ of asthmatic patients [51]. This is particularly relevant in patients with air trapping, in whom a reduction in FVC can lead to a falsely normalized $\mathrm{FEV}_{1} / \mathrm{FVC}$ ratio [52].

The need to remain inside a closed booth during plethysmography can favor storage of droplet aerosols, mainly if the patient coughs during the test. Therefore, this examination should be delayed until local epidemiology is indicative of a low COVID transmission rate. Adequate ventilation of the booth must be guaranteed for at least 15 minutes after each test. In addition to meticulous cleaning and disinfection of the pneumotachograph, the seat and walls and all contact surfaces must be cleaned with nonenzymatic soap or alcoholic solution. The device should be appropriately ventilated, taking into account the recommendations given in Section 2.

\section{Diffusing Capacity}

Diffusing capacity of lung for carbon monoxide (DLCO) represents the gas transfer from alveoli to pulmonary capillaries. According to current guidelines [53], the singlebreath technique is the method of choice, and the GLI (Global
Lung Function Initiative) reference values are available for evaluation [54].

Low DLCO has been generally described in anemia, emphysema, interstitial lung diseases, and pulmonary vascular diseases [48]. Whereas alveolar destruction decreases DLCO, in asthma, DLCO is typically preserved or may even be elevated [55] owing to increased pulmonary blood flow or reduced apparent alveolar volume [56]. Therefore, diffusing capacity can help discriminate between asthma-COPD overlap (ACO) and adult-onset asthma, with lower values of DLCO and DLCO/VA among ACO patients than in those with asthma and fixed airflow limitation [57-59].

In another area, measurement of DLCO is useful for evaluating occupational exposure, mainly the identification of longitudinal decrease in at-risk workers [60]. In hypersensitivity pneumonitis, DLCO is also frequently reduced [61], reaching prognostic significance. In a large cohort of patients with hypersensitivity pneumonitis, the decrease in DLCO was associated with reduced survival, along with older age, a low percentage of lymphocytes in bronchoalveolar lavage, the presence of honeycombing and the usual interstitial pneumonia histologic pattern on the chest radiograph [62]. Moreover, DLCO is sensitive to some therapeutic interventions, such as avoidance of exposure and corticosteroid treatment [63].

Under normal circumstances and with an adequate technique, the risk of transmitting infection via measurement of DLCO is similar to that of spirometry. Therefore, both procedures can be considered from the postpeak phase of COVID pandemic, with a low community prevalence, as long as the required protection and disinfection measures are guaranteed.

\section{Cardiopulmonary Exercise Testing}

Cardiopulmonary exercise testing (CPET) provides an integrative assessment of the physiology of exercise that covers the cardiopulmonary, neuromuscular, and metabolic responses [64]. In patients with asthma, CPET is useful for diagnosis of exercise-induced bronchoconstriction, evaluation of exercise capacity and determination of limiting factors, identification of dynamic hyperinflation [65], and assessment of the response to several therapeutic interventions (Table 3) [66].

Exercise challenge is commonly used to assess the presence of airway hyperresponsiveness [67]. According to American Thoracic Society guidelines [68], the exercise protocol must induce a ventilation of $40 \%$ to $60 \%$ of the maximal voluntary ventilation for at least 4 minutes and is followed by sequential measurements of $\mathrm{FEV}_{1}$. Consequently, hyperventilation is considerable, as is the duration of the test. Exercise-induced bronchoconstriction makes it possible to establish a diagnosis of asthma, especially in individuals with normal spirometry, minimal reversibility, and a high probability of having asthma [43]. Moreover, it can serve to stratify the severity of asthma [69]. Exercise challenge is highly specific for the diagnosis of asthma, mainly in children [70], although its sensitivity is low $[67,71]$.

CPET can precisely define the mechanism of persistent symptoms in patients with difficult asthma and guide tapering of corticosteroids in those without ventilatory limitations [72]. 
Table 3. Summary of the Main Alterations Identified With Cardiopulmonary Exercise Testing in Asthmatic Patients

\begin{tabular}{|c|c|c|}
\hline Functional Disorder & Main Parameters & Characteristic Findings \\
\hline Exercise-induced bronchospasm & $\mathrm{FEV}_{1}$ postexercise & $>10 \%$ fall from baseline value \\
\hline Dynamic hyperinflation & IC during exercise & Any decrease from baseline \\
\hline Exercise intolerance & $\begin{array}{l}\mathrm{VO}_{2} \text { peak, Wpeak } \\
\mathrm{AT}\end{array}$ & $\begin{array}{l}\text { Decreased }(<\mathrm{LLN} \text { or }<75 \% \text { pred.) } \\
\text { Decreased }\left(<40 \% \mathrm{VO}_{2} \max \right)\end{array}$ \\
\hline \multicolumn{3}{|l|}{ Exercise-limiting factors } \\
\hline $\begin{array}{l}\text { Ventilatory mechanical limitation/ } \\
\text { respiratory muscle dysfunction }\end{array}$ & $\begin{array}{l}\mathrm{BR} \\
\text { VT/VE relation } \\
\text { Peak f }\end{array}$ & $\begin{array}{l}\text { Decreased }(<15 \%) \\
\text { Early plateau of VT } \\
\text { Increased }(>55 \text { min- } 1)\end{array}$ \\
\hline Gas exchange limitation & $\begin{array}{l}\mathrm{VE} / \mathrm{VCO}_{2} \\
\text { Peak VD/VT } \\
\mathrm{SpO} 2 \text { during exercise }\end{array}$ & $\begin{array}{l}\text { Increased }(>35 \text { at } \mathrm{AT}) \\
\text { Increased }(>0.25) \\
\text { Desaturation }\left(\Delta \mathrm{SpO}_{2}>4 \%\right)\end{array}$ \\
\hline Pulmonary vascular disease & $\begin{array}{l}\mathrm{AT} \\
\mathrm{VE} / \mathrm{VCO}_{2}\end{array}$ & $\begin{array}{l}\text { Decreased }\left(<30-40 \% \mathrm{VO}_{2} \max \right) \\
\text { Increased }(>35 \text { at AT) }\end{array}$ \\
\hline Cardiac dysfunction & $\begin{array}{l}\text { Peak } \mathrm{VO}_{2} / \mathrm{HR} \\
\text { HR slope } \\
\text { ECG record } \\
\text { Blood pressure }\end{array}$ & $\begin{array}{l}\text { Decreased }(<60 \% \text { pred. }) \\
\text { Increased }(>12.51 / \mathrm{mL} / \mathrm{kg}) \\
\text { Arrhythmia } \\
\Delta \mathrm{DBP}>15 \mathrm{mmHg}\end{array}$ \\
\hline Ischemic cardiac disease & $\begin{array}{l}\text { ECG record } \\
\text { AT } \\
\text { HRR }\end{array}$ & $\begin{array}{l}\text { Alterations of ST segment, Q wave } \\
\text { Normal or low }(<40 \%) \\
\text { Abnormal }(>50 \text { min- } 1)\end{array}$ \\
\hline Deconditioning & $\begin{array}{l}\text { Peak } \mathrm{VO}_{2} / \mathrm{HR} \\
\text { HR slope } \\
\text { Borg dyspnea scale }\end{array}$ & $\begin{array}{l}\text { Normal } \\
\text { Increased }(>12.51 / \mathrm{mL} / \mathrm{kg}) \\
\text { High scores }\end{array}$ \\
\hline Peripheral myopathy & $\begin{array}{l}\text { Serum lactate level } \\
\mathrm{AT} \\
\Delta \mathrm{VO}_{2} / \Delta \mathrm{WR} \\
\text { Borg limb fatigue scale }\end{array}$ & $\begin{array}{l}\text { High }(>\text { reference values of local laboratory) } \\
\text { Low }\left(<40 \% \mathrm{VO}_{2} \mathrm{max}\right) \\
\text { Energetic inefficacy }(>15 \mathrm{~mL} / \mathrm{min} / \mathrm{w}) \\
\text { High Borg fatigue scores }\end{array}$ \\
\hline Anxiety & $\begin{array}{l}\text { Breathing pattern } \\
\mathrm{HR} \\
\text { VE response to } \mathrm{VCO}_{2}\end{array}$ & $\begin{array}{l}\text { Rapid shallow breathing } \\
\text { Resting tachycardia and higher HR during exercise } \\
\text { Higher than reference values }\end{array}$ \\
\hline Motivation & $\begin{array}{l}\text { HR } \\
\text { HRR } \\
\text { AT } \\
\text { RER }\end{array}$ & $\begin{array}{l}\text { Small increase form baseline } \\
\text { High }(>50 \text { min- } 1) \\
\text { Not reached } \\
<1.0\end{array}$ \\
\hline Vocal cord dysfunction & Flow-volume curve during exercise & Inspiratory flow plateau \\
\hline Changes after treatment & $\begin{array}{l}\text { Wpeak } \\
\mathrm{VO}_{2} \text { peak, AT } \\
\text { Isotime VE, BR, VE/ } / \mathrm{VCO}_{2}, \\
\mathrm{VO}_{2} / \mathrm{HR} \text {, or Borg dyspnea }\end{array}$ & $\begin{array}{l}\text { >MCID }(5-10 \mathrm{w}) \\
\text { Significant increase (MCID?) } \\
\text { Any significant increase }\end{array}$ \\
\hline
\end{tabular}

Abbreviations: AT, anaerobic threshold; BDP, diastolic blood pressure; $B R$, breathing reserve; $\Delta V_{2} / \triangle W R$, energetic efficacy; ECG, electrocardiogram;

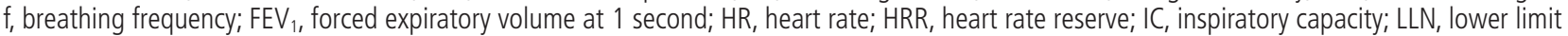
of normal; MCID, minimal clinically important difference; RER, respiratory exchange ratio; $\mathrm{SpO}_{2}$, oxyhemoglobin saturation; $\mathrm{VCO}_{2}$, carbon dioxide production; $\mathrm{VE}$, ventilation; $\mathrm{VE} / \mathrm{VCO}{ }_{2}$, carbon dioxide ventilatory equivalent; $\mathrm{VD} / \mathrm{VT}$, dead space volume/tidal volume ratio; $\mathrm{VO}_{2}$, oxygen uptake; $\mathrm{VO}_{2} / \mathrm{HR}$, oxygen pulse; $\mathrm{VT}$, tidal volume; $\mathrm{W}$, work rate.

Since CPET is also valuable for identifying the physiological changes induced both by asthma and obesity [73,74], it might be applied to assess the cause of breathlessness among obese persons with or without asthma [75].

The duration of CPET and the hyperventilation level achieved increase the risk of emission of aerosols and the transmission of infections. High respiratory flow prevents coupling of bacterial and viral filters in the expiratory ports of many devices. More importantly, there are no data on the retention efficiency of available filters at such high expiratory flows and for prolonged periods. Therefore, CPET should be considered a high-risk procedure and should be delayed until all postpandemic COVID phases are over and the local authorities declare the situation to be under control.

If necessary, consider performing PCR immediately before the procedure to rule out active SARS-CoV-2 infection. Even 
in these circumstances, we recommend maximal protection for technicians and high-level disinfection of all removable components after each test.

\section{Measurement of NO in Exhaled Air}

Fractional exhaled nitric oxide (FeNO) has proven to be an adequate tool, especially in the diagnosis of asthma, and is recommended by high-quality guidelines such as GEMA 5.0 [24] and NICE [76]. It also has a well-documented role in prediction of the response to corticosteroids [77], risk analysis for exacerbations [78], adherence to treatment [79], and assessment of the relevance of exposure to inhalant allergens [80]

The exhalation maneuver is performed at a low flow rate with a sealed device, and its ability to induce cough is much lower than that of the forced spirometry maneuver or provocation tests. In addition, FeNO potentially involves less risk of aerosol generation. The various techniques currently used to analyze exhaled NO concentrations include chemiluminescence, electrochemical sensor devices, and laserbased technology [81]. Simplicity, portability, ease of use, absence of daily calibration processes, and low price have made devices that use electrochemical sensors the approach of choice for clinical use, with chemiluminescence systems reserved for research. Antibacterial/antiviral filters are mandatory in FeNO devices, and it is recommended to perform the same cleaning procedure as for spirometers (see above). Hydroalcoholic solutions are not recommended because alcohol can damage the sensors; therefore, bleach solutions are preferred to clean the surfaces of these devices.

Table 4 summarizes the main performance and safety characteristics of commercially available devices. Currently available systems enable measurement directly from the environment, without the need for a previous inhalation through the device. These systems yield accurate and reproducible measurements. On the other hand, some eNO measurement devices can be operated remotely by connection to laptops or tablets, thus enabling the operator to remain at an adequate distance from the patient while monitoring the test and guiding the patient in the appropriate performance of the maneuver. Finally, some devices, such as evernoa and Vivatmo, offer equipment for home monitoring [84,87]. FeNO monitoring could potentially play a key role in the diagnosis and monitoring of asthma patients in the postpandemic phase [92].

\section{Cytological Analysis of Induced Sputum Samples}

Sputum-induced inflammatory cell counts are currently the most effective noninvasive screening option for bronchial inflammation and a valuable tool for predicting therapeutic responses in patients with asthma $[93,94]$. However, in order to induce expectoration and obtain the induced sputum sample, induction must be performed through an ultrasonic nebulizer, usually with hypertonic saline (at incremental doses). Therefore, this procedure is considered to carry a high risk of contagion in patients with SARS-CoV-2 infection.
Mannitol could also be used to induce sputum samples. Hypertonic saline and mannitol are equally able to produce valuable sputum samples, and the eosinophilic phenotype remains stable in most patients with both stimuli $[95,96]$. Dry powder mannitol challenge is less likely to generate aerosols, although it frequently induces cough [12].

It is important to consider that despite the usefulness of induced sputum in normal clinical practice, this test is complementary, and its results, while not essential, help the professional to make clinical-therapeutic decisions in an appropriate context. For this reason, the test should not be performed in patients with suspected or diagnosed COVID-19 or during the peak period of a coronavirus pandemic.

Given the current uncertainty about the evolution of the COVID-19 pandemic, physicians should be selective when choosing patients and rigorous with respect to the indication, limiting sputum sampling to selected cases in which the result helps direct a treatment that can change the course of the disease. Such a situation would be, for example, the case of a severe asthmatic in whom the initiation of a biological treatment depends on the inflammatory pattern in sputum or in a patient already treated for whom we consider suspending or switching treatment owing to inadequate response $[97,98]$. Therefore, once professionals return to their usual activity and routine post-COVID-19 testing, a series of recommendations should be followed for testing and personal protection, and disinfection measures should be applied as if all patients were suspected of having the disease.

\subsection{Preparing the Patient}

Before the test is prepared, patients must be provided with informative material that explains the measures to be complied with, such as not attending the visit if they develop symptoms of fever or respiratory infection, attending the visit with a surgical mask, and performing adequate hand hygiene. Patients must also receive an explanation on the procedure to be performed.

In a pandemic period, it is advisable to assess the patient 24-72 hours prior to performing the test to search for COVID-19 symptoms. The patient should be questioned about contacts with diagnosed or symptomatic people, and a PCR assay should be performed to detect SARS-CoV-2.

\subsection{Physical Space}

The ideal physical space to perform sputum induction is in negative pressure booths. If these are not available at the test center, a future alternative would be to create booths or areas that have portable fans with high efficiency particulate air (HEPA) filtration [99]. These devices can increase the effective $\mathrm{ACH}$ to the patient's room, thus reducing the risk of people entering the room without respiratory protection. The National Institute for Occupational Safety and Health has developed guidelines for using portable HEPA filtration systems to create suitable patient isolation rooms. The minimum recommended space is $2.5 \times 3 \mathrm{~m}$ because transmission through secretions from infected persons by contact with droplets larger than 5 microns can take place within up to 2 meters. The room should also have patient-accessible tissues (single use only), and waste 


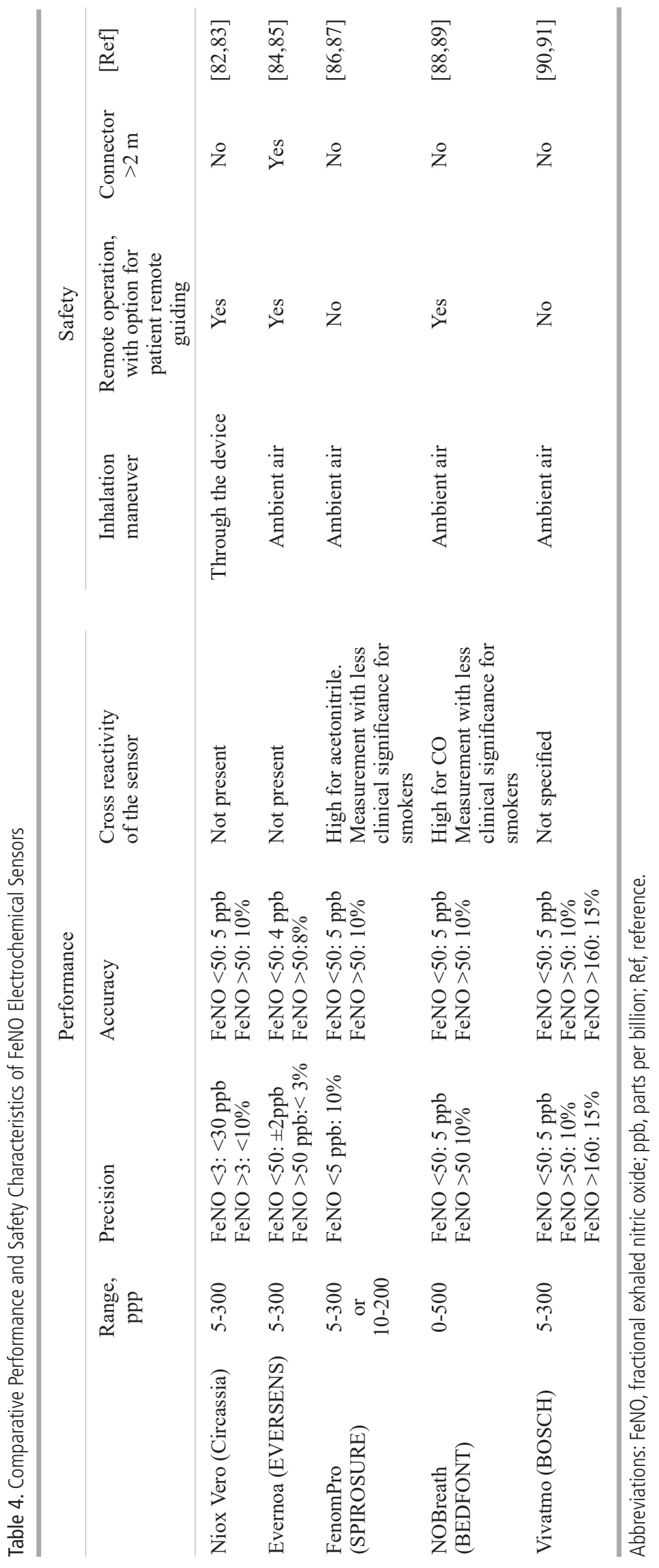


containers with a lid that opens using a foot pedal. The working surfaces of the room should be free of any materials to facilitate subsequent cleaning.

If this physical space is not available, another option would be to have 2 rooms: one for nebulization and stimulation of productive cough, together with an adjoining room separated through a glass where spirometry can be monitored.

The estimated time to achieve correct ventilation in the room where the test is carried out is 15 minutes, and the estimated time for cleaning surfaces and components in a $2.5 \times 3-\mathrm{m}$ room is 5 minutes [11]. The space should be ventilated appropriately and always taking into account the recommendations given in Section 2.

\subsection{Personal Protective Equipment}

Personnel should be provided with a long-sleeved waterproof gown, mask (FPP2, or preferably FPP3, if available), integral frame eye protection or full face shield, double gloves, hydroalcoholic solution (UNE 14476), and closed hospital footwear (patients and staff) for wear before during and after the procedure [99].

\subsection{Induction and Sample Collection}

The personnel performing the induced sputum technique should explain to the patient what induction and sample collection consist of and that a distance of 2 meters should be maintained. They should also explain the procedure for extraction of mucus and placement of the sample in a waterproof, sterilized, disposable container with a screw cap, as well as identification of the sample and transfer with a double bag to the processing site.

For the safety of the test and prior to induction with hypertonic saline, bronchodilator should always be administered with a pressurized metered dose inhaler canister and a double-valve spacer chamber, which can be dismantled for appropriate disinfection.

\subsection{Sample Processing}

Once the sputum sample has been collected, it must be processed in a class II certified biological safety cabinet with additional precautions to provide a barrier between the sample and personnel. Examples of these additional precautions include PPE, such as a surgical mask or face shield, and other physical barriers, such as a splash guard, safety centrifuge cups, and sealed centrifuge rotors to reduce the risk of exposure for laboratory personnel. Before and after working in this type of cabinet, ultraviolet light should be applied for 30 minutes. Each time a tube or other material is introduced or removed from the biosafety cabinet, it should be presprayed with $70 \%$ ( $\mathrm{vol} / \mathrm{vol})$ alcohol or $10 \%$ (vol/ $\mathrm{vol}$ ) bleach. All tubes must be properly capped and closed before removing them from the biosafety cabinet. If possible, use pipette tips with filters to prevent the generation of aerosols [100-102].

\subsection{Cleaning of Material and Physical Space}

Nebulizers and other materials to be used for sputum induction should be cleaned using peracetic acid, STERIS 20, or glutaldehyde-phenolate at a dilution of $1 / 16$ for 10 minutes and 3 minutes, respectively. For cleaning other surfaces, we recommend a virucidal antiseptic (UNE 14476).

The residues generated are considered to be class III or group III special biosanitary waste (similar to tuberculosis). Currently, there is no evidence to suggest that these laboratory residues require additional packaging or disinfection procedures.

\section{Risks and Safety in Upper Airway Diagnostic Tools}

\subsection{Anterior Rhinoscopy and Nasal Endoscopy}

Anterior rhinoscopy enables a quick but limited internal inspection of the anterior parts of the nasal cavities, with evaluation of nasal discharge, mucosal swelling, crusting, septal deviations and perforations, and/or large nasal polyps. Compared with anterior and posterior rhinoscopy, nasal endoscopy offers the advantage of a global evaluation of the endonasal cavity, from the vestibulum to the cavum [103]. Endoscopic examinations such as nasal endoscopy are associated with airborne aerosol production irrespective of whether a rigid or flexible scope is utilized, require prolonged close proximity to the patient, and carry a distinct yet unpredictable risk of triggering sneezing [104]. Extreme care should be taken when performing nasal examination with these tools during COVID-19. Performing RT-PCR immediately before the procedure should be considered.

The objectives of diagnostic nasal endoscopy are as follows: (1) physical examination of the nasal cavities and paranasal sinuses; (2) assessment of nasal abnormalities and severity and follow-up of sinonasal diseases; and (3) biopsy for differential diagnosis [105].

(a) Site conditions

The patient sits in an upright position, and the scope is passed gently through the nasal cavity to the back of the nose.

(b) Safety for personnel and patients

Protection protocols developed for endoscopic procedures include protective clothing, N95 masks, goggles, face shields, and hand and feet covers [106].

\section{(c) Equipment}

Nasal endoscopy is performed using a flexible or rigid scope attached to a light source by glass fiber. An endoscope with an optic angle of $0-45^{\circ}$ and caliber of $2.8-4.0 \mathrm{~mm}$ is used for the diagnostic examination. Endoscopes should be sterilized in liquid for 5 minutes before use.

The Slide-On EndoSheath System is a sterile, disposable cover for flexible endoscopes that provides a latex-free barrier between the scope and the patient. The system is designed to reduce patient contact with organic debris and exposure of staff to hazardous chemicals. When an endoscopic procedure is completed, the sheath is discarded, and the endoscope is wiped with alcohol and reused [107].

\section{(d) Pretreatment}

Pretreatment is not generally mandatory. Local anesthesia (lidocaine, cocaine) may be used if an examination is difficult to perform, bothersome, and/or painful. A nasal decongestant may prove useful, mainly in the presence of nasal deviation, 
turbinate hypertrophy, or swollen mucosa [105]. Individual sets are recommended to prevent viral transmission between physicians and patients during the COVID-19 outbreak.

\subsection{Assessment of Nasal Obstruction and Patency}

\subsubsection{Acoustic rhinometry}

Acoustic rhinometry (AcR) is a noninvasive technique for assessing nasal airway obstruction [108], mainly nasal cavity geometry (volumes and areas). It is indicated in both adults and children [109], in allergic and nonallergic rhinitis, before and after surgery (septoplasty, turbinoplasty, sinus surgery, facial/cosmetic surgery, maxillofacial expansion procedures, adenoidectomy), as well as in antrochoanal atresia, sleep disorders, mechanical nasal dilation, and cleft lip, palate, or nose. It also can also be used for nasal provocation with allergens [110] and aspirin [111].

(a) Site conditions

AcR is a quick (10 seconds per reading), painless, noninvasive, and reliable technique that can be used in both children and adults. It provides a topographic map of nasal blockage with details of type (reversible or nonreversible) and location (anterior and mid, less in posterior) and numerical quantifications of nasal volumes and areas [112]. When needed, and with appropriate preventive measures and nasal cannula sterilization, AcR is the recommended technique for assessment of nasal obstruction in the COVID-19 outbreak.

(b) Safety for personnel and patients

1. Site: both hospital and outpatient settings.

2. Personnel: AcR should be performed by a well-trained physician or nurse.

3. Availability of emergency equipment: not required.

4. PPE: AcR has a low risk of aerosolization. During the COVID-19 outbreak, the health professional should wear an FFP2 or FFP3 face mask, goggles, or disposable face shield.

(c) Equipment

AcR uses an audible reflected sound wave that is converted to produce an area-distance graph. The measurement provides information on nasal structures, either as a measure of nasal volume over a standard distance into the nostril or as the minimal cross-sectional area within the nasal cavity.

(d) Other considerations

Consider single-use equipment or sterilization in cases of direct contact with patients. The examination should be avoided in cases with suggestive respiratory or systemic symptoms that are suggestive of COVID-19.

\subsubsection{Anterior rhinomanometry}

Anterior rhinomanometry is a noninvasive technique for assessing nasal airway obstruction, mainly for nasal patency (flow and resistances). Its indications are similar to those of AcR. Owing to problems in effective material sterilization, this technique is not recommended during the COVID-19 outbreak.

\section{(a) Site conditions}

Active anterior rhinomanometry is a functional test of nasal aerodynamics that measures transnasal airflow (flow rate) and the pressure gradient. Nasal airway obstruction can therefore be evaluated by calculation of nasal resistance [113]

\section{(b) Safety for personnel and patients}

1. Site: both hospital and ambulatory settings.

2. Personnel: anterior rhinomanometry should be performed by a well-trained physician or nurse.

3. Availability of emergency equipment: not required.

4. PPE: Rhinomanometry has a high risk of aerosolization. If AcR is not available, it should be performed with the highest standard of PPE during the COVID-19 outbreak.

\section{(c) Equipment}

Depending on the position of the probes for registration, anterior or posterior rhinomanometry, both of which are valid techniques, can be performed. When the probe is placed in the mouth, posterior rhinomanometry values can be obtained for both nasal cavities together or for one nasal cavity with the other nostril sealed. In anterior rhinomanometry, the pressuresensing tube is placed in one nostril, and unilateral pressure and flow measures are recorded [114].

\section{(d) Other considerations}

In men, shaving improves the seal of the facemask. We recommend avoiding the test during the COVID-19 outbreak. If the examination cannot be delayed, AcR should be preferred.

\subsubsection{Peak Nasal Inspiratory Flow}

Peak nasal inspiratory flow (PNIF) is assessed using an anesthesia mask. Nasal volume and flow are measured in order to assess nasal airway patency. The indications for use are similar to those of AcR and rhinomanometry. Owing to problems in effective material sterilization, this technique is not recommended during the COVID-19 outbreak.

\section{(a) Site conditions}

PNIF is an easy, portable, and inexpensive method for assessing nasal patency. During COVID-19, we recommend performing the test with a single-use mask and placing an antiviral filter between the mask and the PNIF device.

(b) Safety for personnel and patients

1. Site: both hospital and ambulatory settings

2. Personnel: PNIF should be performed by a well-trained physician or nurse.

3. Availability of emergency equipment: not required

4. PPE: PNIF has a high risk of aerosolization [115].

\section{(c) Equipment}

PNIF requires a single-use mask to cover the nose and mouth and measures the maximum volume $(\mathrm{L} / \mathrm{min})$ inspired during a single maximal forced nasal inspiration. The technique can be performed with both nostrils simultaneously or each nostril in turn. It is recommended to record the average reading of the best of 3 maneuvers.

\section{(d) Other considerations}

The examination should be avoided in cases of respiratory or systemic symptoms suggestive of COVID-19. If available, AcR should be preferred over PNIF. In men, shaving improves the seal of the face mask.

\subsection{Nasal Nitric Oxide}

Nasal nitric oxide (nNO) is a colorless and odorless gas present in air exhaled through the mouth or nose and a marker of sinonasal inflammation [116]. 


\section{(a) Site conditions}

Much higher levels (up to 20 times) of nNO are produced in the upper respiratory tract (mainly from the maxillary sinus) than in the lower respiratory tract [117]. nNO can also be measured by chemiluminescence using noninvasive techniques. It is a reliable measure of upper airway inflammation in allergic rhinitis but not in chronic rhinosinusitis with nasal polyps. A marked decrease in $\mathrm{nNO}$ may alert the clinician to a potential defect in mucociliary clearance related to ciliary dyskinesia [114].

(b) Safety for personnel and patients

1. Site: both hospital and ambulatory settings.

2. Personnel: nNO should be performed by a well-trained physician or nurse.

3. Availability of emergency equipment: not required.

4. PPE: nNO has a high risk of aerosolization [115]. nNO should be suspended during the current COVID-19 pandemic [118]. In cases of extreme need, health professionals should use appropriate PPE.

(c) Equipment

Measures similar to those applied for exhaled NO should be taken.

\section{(d) Other considerations}

Inhalation of nitric oxide (NO) is currently being investigated as a preventive measure and as treatment for COVID-19 (clinical trials) [119].

\subsection{Sensory Assessment}

\subsubsection{Smell test/subjective olfactometry}

Subjective olfactometry is a complementary examination used in specific centers with personnel trained in the quantitative assessment of olfactory dysfunction. These tests help to study smell identification, discrimination, and threshold.

\section{(a) Site conditions}

Several culturally adapted techniques are currently available for the objective evaluation of the olfactory capacity of both children and adults [120]. In the COVID-19 outbreak, individual validated smell tests should be preferred.

\section{(b) Safety for personnel and patients}

1. Site: both hospital and ambulatory settings.

2. Personnel: smell tests should be self-administered or performed by a well-trained physician or nurse.

3. Availability of emergency equipment: not required

4. PPE: smell tests have a low-to-high risk of aerosolization depending on the test applied.

\section{(c) Equipment}

The smell test should be validated for the study population, since the various odorants are culture-specific. A universal smell test is available for children (U-sniff) but not for adults.

\section{(d) Other considerations}

Both patients and health professionals should avoid perfumes or body creams on the day of the test. Given the difficulties arising from the COVID-19 pandemic, remote use of validated tools (eg, visual analog scales, ordinal scales, patient-reported outcome measures, telemedicine) cannot be performed face to face owing to the high risk of disease transmission [121, 122]. However, findings should be interpreted with caution [120,123]. Reusable smell tests should be avoided. We encourage single-use tests (eg, self-administered University of Pennsylvania Smell Identification Test [UPSIT]), which contain scratch and sniff microencapsulated odors [124]. If used in countries other than the USA, the test should be properly validated [125].

\subsubsection{Chemical gustometry}

COVID-19 is characterized by smell and taste dysfunctions; therefore, it is mandatory to discriminate between flavor (smell + taste) and real taste [122].

(a) Site conditions

Psychophysical chemical gustatory testing is performed by applying chemical substances to the patient's tongue for the identification of sweet, salty, sour/acidic, or bitter taste perceptions. Gustatory assessment can be achieved by threshold, recognition, and/or supra-threshold measures [120].

(b) Safety for personnel and patients

1. Site: both hospital and ambulatory setting

2. Personnel: gustatory tests are self-administered or performed by a well-trained physician or nurse.

3. Availability of emergency equipment: not required.

4. PPE: gustatory tests have a low risk of aerosolization if individualized test kits are used.

\section{(c) Equipment}

Tastes (sweet, salty, sour/acidic, bitter) should be tested using individualized kits.

\section{(d) Other considerations}

Meals should be avoided for 1 hour before the test. Reusable gustometry tests should be avoided. We encourage single-use, self-administered chemical gustometry tests (individual kits) such as "Taste Strips" [126].

\subsection{Nasal Sampling (Washing, Smear, Biopsies)}

A variety of methods have been used to evaluate inflammation of the nose and sinuses within the nasal mucosa and secretions [127].

(a) Site conditions

These approaches include nasal lavage (the nasal cavity is washed to flush out mucus and debris), cytology (swab of nasal secretions), and nasal biopsy (extraction of cell samples or tissues for histological study).

(b) Safety for personnel and patients

1. Site: both hospital and ambulatory settings.

2. Personnel: the test should be performed by a well-trained physician (biopsies and smears) or nurse (smears).

3. Availability of emergency equipment: a reclining chair or bed should be available for potential vasovagal adverse reactions.

4. PPE: Given the high risk of aerosolization, nonurgent procedures should be avoided during COVID-19 outbreak. If necessary, we recommend performing biopsies and smears with the highest standards of PPE (see above).

\section{(c) Equipment}

Local anesthesia and small forceps for biopsy, saline and syringe for nasal lavage, and swab for nasal smear. 


\section{(d) Other considerations}

It is recommended to avoid this procedure in patients taking anticoagulant therapy. If a procedure is necessary for a COVID-19 patient, consider performing it in a specifically adapted operating room with proper PPE.

\section{Concluding Remarks}

The purpose of this document was to summarize the available information, evidence, and guidance for control of infection relevant to lung function testing, nasal function testing, and other respiratory techniques in the post-SARS$\mathrm{CoV}-2$ era. We hope to facilitate daily practice for researchers and clinicians involved in the management of allergic respiratory diseases such as asthma and allergic rhinitis. Our greatest wish is to learn important lessons from the bitter experience created by the COVID-19 pandemic. These lessons should help us to evaluate patients with the best quality and safety standards, and at the same time add real value to the diagnosis and treatment of their diseases. The changing situation of COVID-19 may require the recommendations made in this review to be modified in the future. While this guidance seeks to ensure a consistently broad approach, some differences in operational details may have to be applied because of local regulations.

\section{Funding}

CIBER de Enfermedades Respiratorias (CIBERES), Spain.

\section{Conflicts of Interest}

Dr Olaguibel reports personal fees from everSens during the conduct of the study, as well as grants from Sanofi, and personal fees from Astra Zeneca, Mundipharma, ALK, and GSK outside the submitted work.

Dr Alobid reports personal fees from Roche, Novartis, MSD, and Menarini outside the submitted work.

Dr Crespo reports personal fees from Novartis, Chiesi España, and Esteve, grants and personal fees from GlaxoSmithKline, personal fees from Ferrer, Zambon, Boehringer Ingelheim, Bial, Teva, and FAES Farma, and grants and personal fees from AstraZeneca outside the submitted work.

Dr Mullol reports personal and other fees from SanofiGenzyme \& Regeneron, Novartis, and Allakos, grants and personal fees from Mylan Pharma and Uriach Group, and personal fees from Mitsubishi-Tanabe, Menarini, UCB, AstraZeneca, GSK, and MSD outside the submitted work.

Dr Plaza reports personal fees and nonfinancial support from GSK, AstraZeneca, Sanofi, Novartis, Mundipharma, Teva, and Allergy Therapeutics outside the submitted work.

Dr Quirce reports personal fees and nonfinancial support from GSK, AstraZeneca, Sanofi, Novartis, Mundipharma, Teva, and Allergy Therapeutics outside the submitted work.

Dr Sastre reports personal fees and nonfinancial support from GSK, AstraZeneca, Sanofi, Novartis, Mundipharma, Teva, and Allergy Therapeutics outside the submitted work.
The remaining authors declare that they have no conflict of interests.

\section{References}

1. Berwick DM. Choices for the "New Normal". JAMA. Published online May 04, 2020. doi:10.1001/jama.2020.6949.

2. Kutter JS, Spronken MI, Fraaij PL, Fouchier RA, Herfst S Transmission routes of respiratory viruses among humans. Curr Opin Virol. 2018;28:142-51.

3. Anfinrud P, Stadnytskyi V, Bax CE, Bax A. Visualizing SpeechGenerated Oral Fluid Droplets with Laser Light Scattering. N Engl J Med. 2020;382:2061-3.

4. Lotfinejad N, Peters A, Pittet D. Hand hygiene and the novel coronavirus pandemic: the role of healthcare workers. J Hosp Infect. 2020:S0195-6701(20)30116-X.

5. Suchomel M, Eggers M, Maier S, Kramer A, Dancer SJ, Pittet D. Evaluation of World Health Organization-Recommended Hand Hygiene Formulations. Emerg Infect Dis. 2020;26(9):2064-8. doi: 10.3201/eid2609.201761.

6. van Doremalen N, Bushmaker T, Morris DH, Holbrook MG, Gamble A, Williamson BN, et al. Aerosol and surface stability of SARS-CoV-2 as compared with SARS-CoV-1. N Engl J Med. 2020:382:1564-7.

7. Lei H, Li Y, Xiao S, Lin CH, Norris SL, Wei D, et al. Routes of transmission of influenza A H1N1, SARS CoV, and norovirus in air cabin: Comparative analyses. Indoor Air. 2018;28:394403.

8. Qian H, Zheng X. Ventilation control for airborne transmission of human exhaled bio-aerosols in buildings. J Thorac Dis. 2018; 10:2295-304.

9. Asadi S, Wexler AS, Cappa CD, Barreda S, Bouvier NM, Ristenpart WD. Aerosol emission and superemission during human speech increase with voice loudness. Sci Rep. 2019;9:2348.

10. Liu Y, Eggo RM, Kucharski AJ. Secondary attack rate and superspreading events for SARS-CoV-2. Lancet. 2020;395:e47.

11. Recommendations from ERS Group 9.1 (Respiratory function technologists/Scientists). Lung function testing during COVID-19 pandemic and beyond. https://www.ersnet.org/ covid-19-guidelines-and-recommendations-directory. (Last accessed May 28, 2020).

12. SEPAR. Recomendaciones de prevención de infección por coronavirus en las unidades de función pulmonar de los diferentes ámbitos asistenciales (Last accessed May 20, 2020).

13. Recomendaciones en Unidades de Función Pulmonar durante Crisis Sanitaria por COVID-19. https://www.seaic.org/ profesionales/noticias-para-profesionales/recomendacionesen-unidades-de-funcion-pulmonar-durante-crisis-sanitariapor-covid-19.html (Last accessed May 28, 2020).

14. Etheridge D, Sandberg M. Building Ventilation - Theory and Measurement. Chichester, UK: John Wiley \& Sons; 1996.

15. Awbi HB. Ventilation in buildings, 2nd edition. Routledge; 2003.

16. WHO, 2007. Infection prevention and control of epidemic- and pandemic-prone acute respiratory diseases in health care - 
WHO interim guidelines. Geneva: World Health Organization; 2007.

17. https://www.who.int/water_sanitation_health/publications/ natural_ventilation.pdf: last accessed May 2020.

18. CDC. Guidelines for environmental infection control in health-care facilities. Morbidity and Mortality Weekly Report. 2003;52(RR-10).

19. Lu J, Gu J, Li K, Xu C, Su W, Lai Z, et al. COVID-19 outbreak associated with air conditioning in a restaurant, Guangzhou, China, 2020. Emerg Infect Dis. 2020;26:7.

20. Li Y, Leung GM, Tang JW, Yang X, Chao CY, Lin JZ, et al. Role of ventilation in airborne transmission of infectious agents in the built environment - a multidisciplinary systematic review. Indoor Air. 2007;17:2-18.

21. Stockwell RE, Ballard EL, O'Rourke P, Knibbs LD, Morawska $L$, Bell SC. Indoor hospital air and the impact of ventilation on bioaerosols: a systematic review. J Hosp Infect. 2019;103(2):175-84.

22. Qian $H$, Zheng X. Ventilation control for airborne transmission of human exhaled bio-aerosols in buildings. J Thorac Dis. 2018; 10(Suppl 19):2295-304.

23. Liang M, Gao L, Cheng C, Zhou Q, Uy JP, Heiner K, et al. Efficacy of Face Mask in Preventing Respiratory Virus Transmission: A Systematic Review and Meta-Analysis. Travel Med Infect Dis. 2020:101751.

24. Verbeek JH, Rajamaki B, ljaz S, Sauni R, Toomey E, Blackwood $B$, et al. Personal Protective Equipment for Preventing Highly Infectious Diseases Due to Exposure to Contaminated Body Fluids in Healthcare Staff. Cochrane Database Syst Rev. 2020;5:CD011621.

25. Chu DK, Akl EA, Duda S, Solo K, Yaacoub K, Schünemann HJ, on behalf of the COVID-19 Systematic Urgent Review Group Effort (SURGE) study authors. Physical distancing, face masks, and eye protection to prevent person-to-person transmission of SARS-CoV-2 and COVID-19: a systematic review and metaanalysis. Lancet. 2020. doi: 10.1016/S0140-6736(20)31142-9.

26. GEMA 5.0. Guía Española para el Manejo del Asma. Editorial luzan5. Madrid 2020. ISBN: 978-84-17372-97-2. Depósito Legal: M-11218-2020. Available at: www.gemasma.com

27. World Health Organzation, Rational use of personal protective equipment for coronavirus disease (COVID-19) and considerations during severe shortages: interim guidance, 6 April 2020 https://apps.who.int/iris/handle/10665/331695. (Last accessed May 28, 2020)

28. Graham BL, Steenbruggen I, Miller MR, Barjaktarevic IZ, Cooper BG, Hall GL, et al. Standardization of Spirometry 2019 Update An Official American Thoracic Society and European Respiratory Society. Technical Statement. Am J Respir Crit Care Med. 2019;200:e70-e88.

29. King GG, Bates J, Berger KI, Calverley $P$, de Melo PL, Dellacà $\mathrm{RL}$, et al. Technical standards for respiratory oscillometry. Eur Respir J. 2020;55: 5-14.

30. Petousi N, Talbot NP, Pavord I, Robbins PA. Measuring lung function in airways diseases: current and emerging techniques. Thorax. 2019;74:797-805.

31. Foy BH, Soares $M$, Bordas R, Richardson M, Bell A, Singapuri $A$, et al. Lung Computational Models and the Role of the Small Airways in Asthma. Am J Respir Crit Care Med. 2019;200(8):982-91.
32. Nair $P$, Martin JG, Cockcroft DC, Dolovich $M$, Lemiere $C$, Boulet LP, et al. Airway Hyperresponsiveness in Asthma: Measurement and Clinical Relevance. J Allergy Clin Immunol Pract. 2017:5(3):649-59 e2.

33. Hallstrand TS, Leuppi JD, Joos G, Hall GL, Carlsen KH, Kaminsky DA, et al; American Thoracic Society (ATS)/European Respiratory Society (ERS) Bronchoprovocation Testing Task Force. ERS technical standard on bronchial challenge testing: pathophysiology and methodology of indirect airway challenge testing. Eur Respir J. 2018;52(5):1801033.

34. Coates AL, Wanger J, Cockcroft DW, Culver BH; Bronchoprovocation Testing Task Force. ERS technical standard on bronchial challenge testing: general considerations and performance of methacholine challenge tests. Eur Respir J. 2017;49(5):1601526.

35. Andregnette-Roscigno $V$, Fernández-Nieto $M$, Del Potro MG, Aguado E, Sastre J. Methacholine is more sensitive than mannitol for evaluation of bronchial hyperresponsiveness in children with asthma. J Allergy Clin Immunol. 2010;126(4):869-71.

36. Jara-Gutierrez $P$, Aguado $E$, Del Potro MG, FernandezNieto M, Mahillo I, Sastre J. Comparison of impulse oscillometry and spirometry for detection of airway hyperresponsiveness to methacholine, mannitol, and eucapnic voluntary hyperventilation in children. Pediatr Pulmonol. 2019;54(8):1162-72.

37. Boulet LP, Gauvreau G, Boulay ME, O'Byrne P, Cockcroft DW; Clinical Investigative Collaboration, Canadian Network of Centers of Excellence AllerGen. The allergen bronchoprovocation model: an important tool for the investigation of new asthma anti-inflammatory therapies. Allergy. 2007;62(10):1101-10.

38. Vandenplas $O$, Suojalehto $H$, Aasen TB, Baur X, Burge PS, de Blay F, et al.; ERS Task Force on Specific Inhalation Challenges with Occupational Agents. Specific inhalation challenge in the diagnosis of occupational asthma: consensus statement. Eur Respir J. 2014;43(6):1573-87.

39. Public Health Ontario: Ontario Agency for Health Protection and Promotion (Public Health Ontario). Focus on: Aerosol generation from coughs and sneezes. Toronto, ON: Queen's Printer for Ontario; 2020. COVID-19: Aerosol Generation from Coughs and Sneezes. April 10, 2020.

40. Public Health England and ARTP (Association for Respiratory Technology and Physiology): COVID19 infection control issues for lung function. https://www.artp.org.uk/write/ MediaUploads/Standards/COVID19/Respiratory_Function_ Testing_During_Endemic_COVID_V1.4.pdf. Last accessed May 21, 2020)

41. Wanger J, Clausen JL, Coates A, Pedersen OF, Brusasco V, Burgos $F$, et al. Standardisation of the measurement of lung volumes. Eur Respir J. 2005;26(3):511-22.

42. Stănescu D, Rodenstein D, Cauberghs M, Van de Woestijne K. Failure of Body Plethysmography in Bronchial Asthma. J Appl Physiol Respir Environ Exerc Physiol. 1982;52(4):939-48.

43. Tepper R, Wise R, Covar R, Irvin C, Kercsmar C, Kraft M, et al. Asthma Outcomes: Pulmonary Physiology. J Allergy Clin Immunol. 2012;129(3 Suppl):S65-87.

44. Luo J, Liu D, Chen G, Liang B, Liu C. Clinical Roles of Lung Volumes Detected by Body Plethysmography and Helium 
Dilution in Asthmatic Patients: A Correlation and Diagnosis Analysis. Sci Rep. 2017;7:40870.

45. Sorkness R, Bleecker E, Busse W, Calhoun W, Castro M, Chung $K$, et al. Lung Function in Adults With Stable but Severe Asthma: Air Trapping and Incomplete Reversal of Obstruction With Bronchodilation. J Appl Physiol (1985). 2008;104(2):394-403.

46. Kraft M, Pak J, Martin R, Kaminsky D, Irvin C. Distal Lung Dysfunction at Night in Nocturnal Asthma. Am J Respir Crit Care Med. 2001;163(7):1551-6.

47. Kraft M, Cairns C, Ellison M, Pak J, Irvin C, Wenzel S. Improvements in Distal Lung Function Correlate With Asthma Symptoms After Treatment With Oral Montelukast. Chest. 2006;130(6):1726-32.

48. Pellegrino R, Viegi G, Brusasco V, Crapo RO, Burgos F, Casaburi $R$, et al. Interpretative strategies for lung function tests. Eur Respir J. 2005;26(5):948-68.

49. Gelb A, Zamel N. Unsuspected Pseudophysiologic Emphysema in Chronic Persistent Asthma. Am J Respir Crit Care Med. 2000;162(5):1778-82.

50. Beuther D, Weiss S, Sutherland E. Obesity and Asthma. Am J Respir Crit Care Med. 2006;174(2):112-9.

51. Miller A, Palecki A. Restrictive Impairment in Patients With Asthma. Respir Med. 2007;101(2):272-6.

52. Brown R, Pearse D, Pyrgos G, Liu M, Togias A, Permutt S. The Structural Basis of Airways Hyperresponsiveness in Asthma. J Appl Physiol (1985). 2006;101(1):30-9.

53. Macintyre N, Crapo RO, Viegi G, Johnson DC, van der Grinten $C P$, Brusasco $V$, et al. Standardisation of the single-breath determination of carbon monoxide uptake in the lung. Eur Respir J. 2005;26(4):720-35.

54. Stanojevic S, Graham B, Cooper B, Thompson B, Carter K, Francis $R$, et al. Official ERS Technical Standards: Global Lung Function Initiative Reference Values for the Carbon Monoxide Transfer Factor for Caucasians. Eur Respir J. 2017:50(3):1700010.

55. Collard P, Njinou B, Nejadnik B, Keyeux A, Frans A. Single Breath Diffusing Capacity for Carbon Monoxide in Stable Asthma. Chest. 1994;105(5):1426-9.

56. Hughes J, Pride N. Examination of the Carbon Monoxide Diffusing Capacity (DL(CO)) in Relation to Its KCO and VA Components. Am J Respir Crit Care Med. 2012;186(2):132-9.

57. Tamada T, Sugiura H, Takahashi T, Matsunaga K, Kimura K, Katsumata U, et al. Coexisting COPD in Elderly Asthma With Fixed Airflow Limitation: Assessment by DLco \%Predicted and HRCT. J Asthma. 2017;54(6):606-15.

58. Tommola $M$, Ilmarinen $P$, Tuomisto L, Lehtimäki L, Haanpää J, Niemelä 0 , et al. Differences Between asthma-COPD Overlap Syndrome and Adult-Onset Asthma. Eur Respir J. 2017:49(5):1602383.

59. Ulrik C, Backer V. Nonreversible Airflow Obstruction in LifeLong Nonsmokers With Moderate to Severe Asthma. Eur Respir J. 1999;14(4):892-6.

60. Hovland K, Skogstad M, Bakke B, Skare Ø, Skyberg K. Longitudinal Decline in Pulmonary Diffusing Capacity Among Nitrate Fertilizer Workers. Occup Med (Lond). 2014;64(3):1817.

61. Baur X. Hypersensitivity Pneumonitis (Extrinsic Allergic Alveolitis) Induced by Isocyanates. J Allergy Clin Immunol. 1995;95(5 Pt 1):1004-10.
62. Ojanguren I, Morell F, Ramón M, Villar A, Romero C, Cruz $\mathrm{M}$, et al. Long-term Outcomes in Chronic Hypersensitivity Pneumonitis. Allergy. 2019;74(5):944-52.

63. Morisset J, Johannson K, Vittinghoff $E$, Aravena C, Elicker $B$, Jones K, et al. Use of Mycophenolate Mofetil or Azathioprine for the Management of Chronic Hypersensitivity Pneumonitis. Chest. 2017;151(3):619-25.

64. ATS/ACCP Statement on cardiopulmonary exercise testing. Am J Respir Crit Care Med. 2003;167(2):211-77.

65. Ferreira $P$, Freitas $P$, Silva $A$, Porras $D$, Stelmach $R$, Cukier $A$, et al. Dynamic Hyperinflation and Exercise Limitations in Obese Asthmatic Women. J Appl Physiol (1985). 2017;123(3):585-93.

66. Boutou A, Daniil Z, Pitsiou G, Papakosta D, Kioumis I, Stanopoulos I. Cardiopulmonary Exercise Testing in Patients With Asthma: What Is Its Clinical Value? Respir Med. 2020;167:105953.

67. Joos G, O'Connor B, Anderson S, Chung F, Cockcroft D, Dahlén $\mathrm{B}$, et al. Indirect Airway Challenges. Eur Respir J. 2003;21(6):1050-68.

68. Crapo R, Casaburi R, Coates A, Enright P, Hankinson J, Irvin $C$, et al. Guidelines for Methacholine and Exercise Challenge testing-1999. This Official Statement of the American Thoracic Society Was Adopted by the ATS Board of Directors, July 1999. Am J Respir Crit Care Med. 2000;161(1):309-29.

69. Lazo-Velásquez J, Lozada A, Cruz H. Evaluation of Severity of Bronchial Asthma Through an Exercise Bronchial Challenge. Pediatr Pulmonol. 2005;40(5):457-63.

70. Eliasson A, Phillips Y, Rajagopal K, Howard R. Sensitivity and Specificity of Bronchial Provocation Testing. An Evaluation of Four Techniques in Exercise-Induced Bronchospasm. Chest. 1992;102(2):347-55.

71. De Baets F, Bodart E, Dramaix-Wilmet M, Van Daele $S$, de Bilderling G, Masset $S$, et al. Exercise-induced Respiratory Symptoms Are Poor Predictors of Bronchoconstriction. Pediatr Pulmonol. 2005;39(4):301-5.

72 McNicholl D, Megarry J, McGarvey L, Riley M, Heaney L. The Utility of Cardiopulmonary Exercise Testing in Difficult Asthma. Chest. 2011;139(5):1117-23.

73. Beuther D, Sutherland E. Overweight, Obesity, and Incident Asthma: A Meta-Analysis of Prospective Epidemiologic Studies. Am J Respir Crit Care Med. 2007;175(7):661-6.

74. Stenius-Aarniala B, Poussa $T$, Kvarnström J, Grönlund $E_{\text {, }}$ Ylikahri M, Mustajoki P. Immediate and Long Term Effects of Weight Reduction in Obese People With Asthma: Randomised Controlled Study. BMJ. 2000;320(7238):827-32.

75. Carpio C, Villasante C, Galera R, Romero D, de Cos A, Hernanz $A$, et al. Systemic Inflammation and Higher Perception of Dyspnea Mimicking Asthma in Obese Subjects. J Allergy Clin Immunol. 2016:137(3):718-26.

76. Asthma: diagnosis and monitoring of asthma in adults children and young people. www.nice.org.uk/guidance/ng80/ evidence/full-guideline-asthma-diagnosis-andmonitoringpdf-4656178047 (Last accessed Dec 4, 2017).

77. Price DB, Buhl R, Chan A, Freeman D, Gardener E, Godley $C$, et al. Fractional exhaled nitric oxide as a predictor of response to inhaled corticosteroids in patients with nonspecific respiratory symptoms and insignificant bronchodilator reversibility: a randomised controlled trial. Lancet Respir Med. 2018;6(1):29-39. 
78. Menzies-Gow A, Mansur AH, Brightling CE. Clinical utility of fractional exhaled nitric oxide in severe asthma management. Eur Respir J. 2020;55(3):1901633.

79. Heaney LG, Busby J, Bradding P, Chaudhuri R, Mansur AH, Niven $\mathrm{R}$, et al. Remotely Monitored Therapy and Nitric Oxide Suppression Identifies Nonadherence in Severe Asthma. Am J Respir Crit Care Med. 2019;199(4):454-64.

80. Kalm-Stephens $P$, Nordvall $L$, Janson C, Neuman A, Malinovschi A, Alving K. Elevated Exhaled Nitric Oxide in Adolescents Is Associated With Incident Allergic Symptoms: A Prospective Cohort Study. J Investig Allergol Clin Immunol. 2019;29(3):231-8.

81. Maniscalco M, Vitale C, Vatrella A, Molino A, Bianco A, Mazzarella G. Fractional exhaled nitric oxide-measuring devices: technology update. Med Devices (Auckl). 2016;9:15160. 6 .

82. CIRCASSIA (Online) https://www.niox.com/en/coronavirusfaq/. (Last accessed 20.05.2020). 7.

83. CIRCASSIA [Online] [Last accessed: May 20, 2020] https:// www.niox.com/pdf/niox-vero-user-manual-es.pdf.

84. EVERSENS [Online] [Last accessed: May 20, 2020.] http:// www.evernoa.com

85. Olaguibel $A$, Oleaga $M$, Cortaberría $R$, Corcuera $A$, Álvarez Puebla MJ, Tabar A, I. Exhaled Nitric Oxide (eNO) Measurements With the New Evernoa ${ }^{\circledR}$ Device Are Valid and Reproducible Through an Extended Range of eNO Levels. J Investig Allergol Clin Immunol. 2020;30(2):147-9.

86. FDA [Online] [Last accessed: May 20, 2020.] https://www. accessdata.fda.gov/cdrh_docs/pdf18/K182874.pdf.

87. Spirosure [Online] [Last accessed: May 20, 2020] https:// fenomasthma.com/wp-content/uploads/2018/09/MKT-3329Rev-A-Spec-Sheet-2.pdf.

88. BEDFONT [Online] [Last accessed: May 20, 2020] https://www. nobreathfeno.com/coronavirus-and-the- 2 nd-generationnobreath-update/

89. Bedfont [Online] [Last accessed: May 20, 2020.] https://www. nobreathfeno.com/wp-content/uploads/2020/03/MKT506NObreath-V2-datasheet-issue-6.pdf

90. BOSCH [Online] [Last accessed: May 20, 2020.] https://www. vivatmo.com/en/faq/

91. BOSCH [Online] [Last accessed: May 20, 2020.] https://www. vivatmo.com/en/healthcare-professionals/downloads/

92. Bernstein JA, Davis B, Alvarez-Puebla MJ, Levin L, Olaguibel JM. Is exhaled nitric oxide a useful adjunctive test for assessing asthma? J Asthma. 2009;46(9):955-60.

93. Olaguibel JM, Alvarez MJ, Garcia B. Inflammatory phenotypes in nonsmoking asthmatic patients. J Investig Allergol Clin Immunol. 2011;21(3):249-50.

94. Suárez-Cuartín G, Crespo A, Mateus E, Torrejón M, Giner J, Belda $A$, et al. Variability in asthma inflammatory phenotype in induced sputum. Frequency and causes. Arch Bronconeumol (English Edition). 2016;52(2):76-81.

95. Alvarez-Puebla MJ, Olaguibel JM, Almudevar E, Echegoyen AA, Vela C, de Esteban B. Mannitol versus hypertonic saline: Safety and efficacy of mannitol and hypertonic saline in sputum induction and bronchial hyperreactivity assessment. Chron Respir Dis. 2015;12(3):197-203.

96. Wood LG, Powell H, Gibson PG. Mannitol challenge for assessment of airway responsiveness, airway inflammation and inflammatory phenotype in asthma. Clin Exp Allergy. 2010;40:232-41.

97. Dávila I, Quirce S, Olaguibel J. Selection of Biologics in Severe Asthma: A Multifaceted Algorithm. J Investig Allergol Clin Immunol. 2019;29(4):325-8.

98. Alvarez-Puebla M, Arroabarren E, Zavala M, Corcuera A, Olaguibel A, Olaguibel J. Responses to Biological Therapy in Severe Eosinophilic Asthma. J Investig Allergol Clin Immunol. 2019;29(4):335.

99. Information for Healthcare Professionals about Coronavirus (COVID-19). Coronavirus Disease 2019. Available at: https:// www.cdc.gov/coronavirus/2019-nCoV/hcp/index.html

100. Interim Laboratory Biosafety Guidelines for Handling and Processing Specimens Associated with Coronavirus Disease 2019 (COVID-19). May 2020. Available at: https://www.cdc. gov/coronavirus/2019-nCoV/lab/

101. ECDC. Infection prevention and control for the care of patients with 2019-nCoV in healthcare settings. Feb 2020. Available at: https://www.ecdc.europa.eu/sites/default/files/ documents/nove-coronavirus-infectionprevention-controlpatients-healthcare-settings.pdf

102. WHO. Laboratory biorisk management for laboratories handling human specimens suspected or confirmed to contain novel coronavirus: Interim recommendations. Feb 2013. Available at: https://www.who.int/csr/disease/ coronavirus_infections/Biosafety_InterimRecommendations_ NovelCoronavirus_19Feb13.pdf

103. Hellings PW, Scadding G, Alobid I, Bachert C, Fokkens WJ, Gerth van Wijk R, et al. Executive summary of European Task Force document on diagnostic tools in rhinology. Rhinology. 2012;50(4):339-52.

104. Workman $A D$, Jafari $A$, Welling $D B$, Varvares MA, Gray $S T$, Holbrook EH, et al. Airborne Aerosol Generation During Endonasal Procedures in the Era of COVID-19: Risks and Recommendations. Otolaryngol Head Neck Surg. 2020:194599820931805.

105. Kowalski ML, Ansotegui I, Aberer W, Al-Ahmad M, Akdis M, Ballmer-Weber BK, et al. Risk and safety requirements for diagnostic and therapeutic procedures in allergology: World Allergy Organization Statement. World Allergy Organ J. 2016:9(1):33.

106. Patel ZM, Fernandez-Miranda J, Hwang PH, Nayak JV, Dodd $\mathrm{R}$, Sajjadi $\mathrm{H}$, et al. Precautions for Endoscopic Transnasal Skull Base Surgery During the COVID-19 Pandemic. Neurosurgery. 2020. doi: 10.1093/neuros/nyaa125

107. Vaz F, Ripley L, Lim D, Kanegaonkar R, Harries M. Optical quality of the nasendoscope with and without the endosheath. J Laryngol Otol. 2006;120(5):385-8.

108. Valero A, Serrano C, Bartrá J, Izquierdo I, Muñoz-Cano R, Mullol $J$, et al. Reduction of nasal volume after allergen-induced rhinitis in patients treated with rupatadine: a randomized, cross-over, double-blind, placebo-controlled study. J Investig Allergol Clin Immunol. 2009;19(6):488-93.

109. Distinguin L, Louis B, Baujat G, Amaddeo A, Fauroux B, Couloigner $V$, et al. Evaluation of nasal obstruction in children by acoustic rhinometry: A prospective study. Int J Pediatr Otorhinolaryngol. 2019;127:109665.

110. Augé J, Vent J, Agache I, Airaksinen L, Campo Mozo P, Chaker $A$, et al. EAACI position paper on the standardization of nasal allergen challenge. Allergy. 2018;73:1597-608. 
111. Kowalski ML, Agache I, Bavbek S, Bakirtas A, Blanca M, Bochenek $G$, et al. Diagnosis and management of NSAIDExacerbated Respiratory Disease (N-ERD) - A EAACI position paper. Allergy. 2019;74:28-39.

112. Corey JP. Acoustic rhinometry: should we be using it? Curr Opin Otolaryngol Head Neck Surg. 2006;14(1):29-34.

113. Valero A, Navarro AM, Del Cuvillo A, Alobid I, Benito JR, Colás $C$, et al. Position paper on nasal obstruction: evaluation and treatment. J Investig Allergol Clin Immunol. 2018;28(2):67-90.

114. Scadding G, Hellings P, Alobid I, Bachert C, Fokkens W, van Wijk RG, et al. Diagnostic tools in Rhinology EAACl position paper. Clin Transl Allergy. 2011;1(1):2.

115. AAAA. Suggestions or considerations for resuming practices. AAAA 2020. https://education.aaaai.org/resources-for-a-i-clinicians/ prepare-your-practice_covid-19. Accessed May 17, 2020.

116. Tworek D, Kuna P. Nasal nitric oxide measurements in the assessment of nasal allergen challenge. J Investig Allergol Clin Immunol. 2012;22(2):102-8.

117. Kawamoto $H$, Takumida $M$, Takeno $S$, Watanabe $H$, Fukushima N, Yajin K. Localization of nitric oxide synthase in human nasal mucosa with nasal allergy. Acta Otolaryngol. 1998;539(Suppl):65-70.

118. Pfaar 0 , Klimek L, Jutel M, Bousquet J, Breiteneder H, Diamant Z, et al. COVID-19 pandemic: Practical considerations on the organization of an allergic clinic - an EAACI/ARIA Position Paper. Allergy. 2020 [Epub ahead of print.]

119. Martel J, Ko YF, Young JD, Ojcius DM. Could nasal nitric oxide help to mitigate the severity of COVID-19? Microbes Infect. 2020;51286-4579(20)30080-0

120. Hummel T, Whitcroft KL, Andrews P, Altundag A, Cinghi C, Costanzo RM, et al. Position paper on olfactory dysfunction. Rhinol Suppl. 2017;54(26):1-30.

121. Mullol J, Mariño-Sanchez F, Valls M, Alobid I, Marin C. Smell in chronic rhinosinusitis. J Allergy Clin Immunol. 2020;145:7736.
122. Izquierdo-Domínguez A, Rojas-Lechuga MJ, Mullol J, Alobid I. Olfactory dysfunction in the COVID-19 outbreak. J Investig Allergol Clin Immunol. 2020 [Epub ahead of print].

123. Whitkroft KL, Hummel T. Olfactory dysfunction in COVID-19: Diagnosis and management. JAMA. 2020 [Epub ahead of Print] doi: 10.1001/jama.2020.8391.

124. Doty RL. Studies of human olfaction from the University of Pennsylvania Smell and Taste Center. Chem Senses. 1997;22(5):565-86.

125. Mariño-Sánchez $F$, Santamaría A, de los Santos G, Alobid I, Mullol J. Psychophysical olfactory testing in COVID-19: is smell function really impaired in nearly all patients? Int Forum Allergy Rhinol. 2020 [Epub ahead of Print].

126. Landis BN, Welge-Luessen $A$, Brämerson A, Bende M, Mueller CA, Nordin S, et al. "Taste Strips" - a rapid, lateralized, gustatory bedside identification test based on impregnated filter papers. J Neurol. 2009;256(2):242-8.

127. Serrano CD, Valero A, Bartra J, Roca-Ferrer J, MuñozCano R, Sánchez-López J, et al. Nasal and bronchial inflammation after nasal allergen challenge: assessment using noninvasive methods. J Investig Allergol Clin Immunol. 2012;22(5):351-6. Manuscript received June 11, 2020; accepted for
publication June 16, 2020 .

\section{- Jose M Olaguibel}

E-mail: jm.olaguibel.rivera@navarra.es 